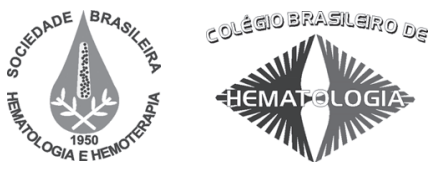

\title{
Células-tronco de origem hematopoética: expansão e perspectivas de uso terapêutico
}

\author{
Hematopoietic stem cells: expansion and perspectives for therapeutic use
}

Eliana S. F. W. Abdelhay ${ }^{l}$

Flávio H. Paraguaçú-Braga ${ }^{2}$

Renata Binato ${ }^{3}$

Luis Fernando S. Bouzas ${ }^{4}$
A célula-tronco hematopoética (CTH) tem um enorme potencial para reconstituir o sistema hematopoético, o que permitiu o desenvolvimento de estratégias de terapias celulares para doenças neoplásicas ou não. Em paralelo com os avanços clínicos, estudos sobre os mecanismos moleculares que levam as células-tronco hematopoéticas a decidir pela autorrenovação, diferenciação ou apoptose têm contribuído para o conhecimento de como controlar a cinética da CTH. Esta revisão tenta descrever como estes novos avanços podem ser utilizados no desenvolvimento de estratégias de expansão das CTHs para uso terapêutico. Rev. Bras. Hematol. Hemoter. 2009;31(Supl. 1):2-8.

Palavras-chave: Células-tronco hematopoéticas; expansão; terapia celular.

\section{Introdução}

Células-tronco são células capazes tanto de diferenciação, para produzir células filhas maduras, como de autorrenovação, que irá sustentar e repopular o reservatório de células-tronco.

As células-tronco têm um papel crítico durante o desenvolvimento no estabelecimento dos tecidos embriônicos e, em alguns casos, são mantidas na vida adulta, onde elas irão atuar na produção de células maduras em sistemas nos quais as células têm vida curta, e também na regeneração de tecidos que foram danificados por injúria ou degeneração.

As células-tronco hematopoéticas (CTHs) são as mais extensivamente estudadas. Células sanguíneas maduras são predominantemente de curta duração, o que exige que CTHs sejam renovadas durante toda a vida do indivíduo de forma a produzir progenitores multilinhagens e precursores direcionados a linhagens hematopoéticas individuais.
As CTHs residem como raras células na medula óssea de mamíferos adultos (tipicamente de $0,01 \%$ a $0,05 \%$ ), podendo também circular no sangue periférico, onde sua concentração é ainda menor ( $0,001 \%)$. Células-tronco hematopoéticas são geradas durante o desenvolvimento, podendo ser encontradas também no fígado fetal e em sangue do cordão umbilical (SCUP). ${ }^{1}$

\section{Células-tronco hematopoéticas}

As células-tronco hematopoéticas podem ser divididas em três tipos: células-tronco hematopoéticas com capacidade de autorrenovação a longo-termo (LT-CTH), célulastronco hematopoéticas com capacidade a curto termo (CT$\mathrm{CTH}$ ) e progenitores multilinhagem (PM) que, aparentemente, são incapazes de se autorrenovar. Enquanto as LT-CTHs são consideradas capazes de se renovar indefinidamente, sendo responsáveis por repopular todo o sistema hematopoético, as CT-CTHs e os progenitores multilinhagem têm

${ }^{I}$ Chefe da Divisão de Laboratórios do Cemo-Inca - Rio de Janeiro-RJ.

${ }^{2}$ Supervisor do Banco de Sangue de Cordão Umbilical e Placentário do Cemo-Inca - Rio de Janeiro-RJ.

${ }^{3}$ Tecnologista do Laboratório de Célula-Tronco do Cemo-Inca - Rio de Janeiro-RJ.

${ }^{4}$ Diretor do Cemo-Inca - Rio de Janeiro-RJ.

Centro de Transplante de Medula Óssea, Instituto Nacional de Câncer - Rio de Janeiro-RJ.

Correspondência: Eliana Abdelhay

Praça da Cruz Vermelha 23, $7^{\circ}$ andar - Cemo/Inca

20230-130 - Rio de Janeiro-RJ - Brasil

Tel.: (55 21)2506-6691 - Fax.: (55 21) 2509-2121

E-mail: eabdelhay@inca.gov.br

Doi: 10.1590/S1516-84842009005000019 
curta duração, sendo capazes de manter a hematopoese de um camundongo irradiado por no máximo quatro meses. ${ }^{2,3}$ Estes conhecimentos mostram que, para se utilizarem CTHs em terapias celulares, a célula de escolha é a LT-CTH.

A identificação e separação destas diferentes populações de células recaem sobre combinações de marcadores de superfície, uma vez que nenhuma delas possui um marcador exclusivo. Assim, numa fração enriquecida em LT-CTHs, as células mononucleadas são selecionadas pelo imunofenótipo

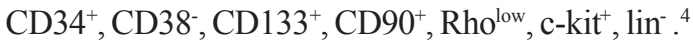

Devido à raridade das $\mathrm{CTHs}$ nos diferentes tecidos hematopoéticos $\left(1 / 9 \times 10^{5} \mathrm{CMN}\right.$ no SCUP ou $1 / 3 \times 10^{6}$ na medula óssea $)^{5}$ e à dificuldade de se diferenciar entre as populações LT-CTHs, CT-CTHs e PM, a possibilidade de produção in vitro de células é uma maneira de suplementar o número limitado de células para uso em terapias celulares.

\section{Capacidade terapêutica da célula-tronco hematopoética}

O grande potencial que as CTHs mostram na reconstituição do sistema hematopoético levou ao desenvolvimento de estratégias de transplante de CTHs na prática clínica. Os primeiros transplantes foram realizados utilizando-se células da medula óssea, mas células do sangue periférico e do sangue do cordão umbilical são hoje em dia utilizadas da mesma forma. ${ }^{6,7}$

Os transplantes de células-tronco hematopoéticas apresentam resultados clínicos variados no tratamento de doenças malignas e não malignas. Estes resultados tanto dependem da doença de base e do estado clínico do paciente quanto do número de células de cada tipo que são infundidas. Neste sentido, a recuperação tanto de neutrófilos quanto de plaquetas está correlacionada ao número de precursores granulocíticos-mielóides infundidos, enquanto a recuperação imunológica depende das células $\mathrm{T}$ maduras infundidas. ${ }^{8}$ Tendo em vista que, até a recuperação destes componentes do sistema, o paciente tem risco elevado de complicações por infecções, estratégias que combinem a infusão de um número elevado de LT-CTHs associadas a progenitores GM e células T maduras podem melhorar as estratégias terapêuticas.

Um exemplo em que isto seria importante é o transplante haploidêntico. Neste caso, um dos pais do paciente serve de doador de CTHs, o que garante a existência de doador na maioria dos casos. No entanto, nesta estratégia, existe um alto grau de mismatch dos antígenos de histocompatibilidade (HLA), portanto, o produto a ser infundido é geralmente depletado de células T do doador.'

Quando se utilizam infusões não depletadas de células $\mathrm{T}$, a reconstituição imunológica inicial é realizada a partir de células T maduras do doador. Por outro lado, infusões depletadas de células $\mathrm{T}$, apesar de reduzirem a incidência da doença do enxerto contra hospedeiro (DECH), dependem da produção "de novo" de células T pelo timo do receptor, o que exige um tempo consideravelmente maior para a recuperação imunológica. ${ }^{10}$

Experimentos indicam que, em transplantes haploidênticos pediátricos $\left(>20 \times 10^{6}\right.$ células $\left./ \mathrm{kg}\right)$, o aumento do número de células CD34+ infundidas diminui o tempo de recuperação imunológica, ${ }^{11}$ no entanto, nem sempre é possível obter-se esta quantidade de células de um doador. Portanto, a possibilidade de se amplificarem in vitro as CTHs do doador poderia melhorar a recuperação imunológica e expandir o uso dos transplantes com doadores parentais.

\section{Células-tronco do cordão umbilical}

Uma importante fonte de células-tronco hematopoéticas é o sangue do cordão umbilical, que pode ser colhido logo após o nascimento. Além da grande disponibilidade deste material, essas células (CTHs) têm outras propriedades importantes para seu uso em terapias celulares, incluindo sua habilidade reduzida em induzir reatividade imunológica contra receptor.

Desde o primeiro transplante com CTHs de sangue de cordão umbilical, em 1988, esta fonte tem sido utilizada de forma crescente. ${ }^{12}$

O sangue de cordão umbilical contém uma subpopulação de células $\mathrm{CD} 34^{+}$mais primitiva, que mostra uma capacidade de expansão maior quando na presença de ligante de FLT-3, ligante de Kit e trombopoetina (TPO) em comparação com as células correlatas existentes no sangue periférico mobilizado. Por outro lado, diversos estudos mostram que LT-CTHs de SCUP podem se diferenciar em progenitores funcionais em condições de cultura específicas.

Apesar das várias vantagens, o uso de CTHs de SCUP é limitado pelo número de $\mathrm{CTHs}$ que podem ser coletadas e infundidas, tornando esta fonte de CTHs quase limitada a transplantes pediátricos. ${ }^{13} \mathrm{Na}$ tentativa de eliminar esta limitação, protocolos de expansão ex vivo têm sido desenvolvidos com sucessos relativos.

\section{Expansão ex vivo de CTHs}

As CTHs são capazes de uma expansão in vivo estimada de 8 mil vezes. ${ }^{14}$ Este nível de expansão, se in vitro, pode impactar a estabilidade genética da célula assim como seu potencial de desenvolvimento pela perda de telômero ${ }^{15}$ e pelo estresse oxidativo. ${ }^{16}$ No entanto, expansão muito mais modesta, na ordem de cem vezes, já teria um impacto terapêutico.

Um enorme esforço tem sido efetuado no sentido de definir as condições de cultura ideais para suportar a expansão das CTHs. Um aspecto particularmente investigado tem sido o coquetel de citocinas que simultaneamente iniba a apoptose, induza a mitose e previna a diferenciação. ${ }^{17-19}$ Além disso, muitos outros aspectos da cultura têm sido otimizados, como o recipiente de cultura, a densidade de semeadura, o 
tipo de fração celular a utilizar para iniciar a cultura, os protocolos de manutenção e repique assim como composição do meio e a tensão de oxigênio..$^{20-22}$

Citocinas são proteínas secretadas que regulam muitos aspectos da hematopoese, como a resposta imune e a inflamação. Muitas citocinas foram identificadas e purificadas devido à sua habilidade de formação de colônias hematopoéticas a partir de progenitores. Subsequentemente, várias destas citocinas mostraram ligar-se a receptores na superfície das CTHs e regular várias de suas funções, como quiescência, autorrenovação, diferenciação, apoptose e mobilidade. Portanto, uma questão relevante é saber que células secretam que citocinas e em que lugar e como as diferentes CTHs respondem a este estímulo.

As primeiras tentativas de expansão de CTHs basearam-se no uso de citocinas hematopoéticas. Por exemplo, CTHs de camundongos são estimuladas a divisões de autorrenovação quando expostas a IL-3, IL-6 e SCF (stem cell factor $)^{23-25}$ enquanto CTHs humanas proliferam quando expostas a Flt-3 e trombopoetina. ${ }^{26,27}$ No entanto, estas expansões não ultrapassam quatro vezes o número de células iniciais. ${ }^{28}$

Misturas de citocinas usualmente utilizadas para suplementar culturas de CTHs livres de soro em geral são constituídas por IL-3, IL-6, SCF, TPO e FLT-3 com adição ou não de outros fatores.

O fator de célula-tronco (SCF) é uma citocina expressa por diversos tipos celulares que se liga a seu receptor c-kit, uma tirosina quinase expressa em todas as CTHs. Apesar da SCF não ser essencial para geração de CTHs, estudos têm demonstrado que a sinalização SCF/c-kit previne a apoptose destas células aumentando a chance de expansão. ${ }^{29}$

A trombopoetina (TPO) é a citocina que regula a produção de megacariócitos e plaquetas. No entanto, a TPO e seu receptor Mpl têm efeitos importantes em células hematopoéticas primitivas. Tanto o camundongo nocaute para TPO quanto para $\mathrm{Mpl}$ tem velocidade diminuída de repopulação das CTHs. ${ }^{30}$ Por outro lado, estudos in vitro indicam que a TPO tem um papel de promoção da sobrevivência das CTHs em expansão. ${ }^{31}$

Outro aspecto importante na expansão ex vivo de CTHs é a presença de células acessórias que mimetizem o ambiente medular. Estas células têm um papel importante no condicionamento do ambiente onde a expansão irá ocorrer, produzindo citocinas que irão regular a hematopoese.

Culturas livre de soro, contendo um estroma previamente obtido, são mais efetivas na manutenção das células com um fenótipo mais primitivo. Por outro lado, culturas suplementadas com várias combinações de fatores de crescimento humano recombinantes mostram uma prevalência para a diferenciação das $\mathrm{CTHs} .{ }^{32}$

Coculturas estroma-CTHs têm sido bastante estudadas no sistema desenvolvido por Dexter et al. ${ }^{33}$ Neste sistema, uma cultura em duas camadas (2D) é formada e o contato entre elas tem sido considerado essencial. ${ }^{34}$ No entanto, a expansão neste sistema tem demonstrado estar limitada à linhagem granulocítica.

A produção de células estromais humanas derivadas de tecidos fetais como o saco vitelínico e a aorta-gônadamesonéfrons permitiu a expansão de células-tronco de longo termo ${ }^{35}$ enquanto linhagem estromal obtida da medula óssea humana só demonstrou suportar a expansão de células progenitoras.

Apesar destes avanços, o nível de expansão obtido tanto para as LT-CTHs como para progenitores não atingiu até hoje os patamares desejados.

Para tentar superar estas dificuldades, sistemas de cultivo em larga escala em biorreatores utilizando ou não células estromais e citocinas recombinantes foram desenvolvidos e testados. Os sucessos obtidos foram pequenos e, na maioria dos experimentos, a expansão prevalente foi de células progenitoras. ${ }^{36}$

Simultaneamente a estes avanços, interesses em melhor entender os mecanismos básicos de controle de replicação e diferenciação das CTHs introduziram paulatinamente novos conhecimentos que podem impactar a geração de tecnologias de expansão e novas abordagens terapêuticas.

\section{A influência do nicho hematopoético}

O nicho hematopoético pode ser definido como um espaço regulatório anatomicamente confinado capaz de governar o número e a determinação das CTHs. Vários tipos celulares contribuem para o nicho hematopoético, incluindo os osteoblastos, o endotélio ou células perivasculares, células estromais, osteoclastos, adipócitos, assim como células hematopoéticas.

As células-tronco dependem do microambiente onde estão inseridas no nicho para realizar as atividades de autorrenovação e de diferenciação. Como em vertebrados o sítio de hematopoese muda ao longo do desenvolvimento, as características do nicho e a sinalização provavelmente são específicas em cada momento.

A maior parte das informações disponíveis em mamíferos é relativa à medula óssea do adulto. Trabalhos recentes têm indicado o papel de populações celulares que contribuem para manter as interações entre o nicho e as CTHs. Sachetti et al. ${ }^{37}$ identificaram uma população de células estromais subendoteliais que expressam CD146 e parecem ser importantes para a capacidade de autorrenovação das CTHs. Estas células expressam altos níveis da quimiocina CXCL-12/SDF1, característica que é compartilhada por outra célula estromal, as células reticulares. Estas células circundam as células endoteliais dos sinusoides ou estão localizadas perto do endósteo. Aparentemente, as CTHs perto do endotélio sinusoidal estão em contato com estas células reticulares.

A importância desta sinalização para a manutenção e autorrenovação das CTHs é sugerida em experimentos com 
o camundongo nocaute para o receptor de CXCL-12, CXCR4. Estes animais mostram uma severa redução no número de CTHs. ${ }^{38}$

Como na medula óssea dos adultos as CTHs estão localizadas perto da superfície óssea endostal e do endotélio dos sinusoides, estes sítios constituem o principal nicho hematopoético em condições fisiológicas. Portanto, a sinalização SDF1 e seu receptor CXCR4 parecem ter um papel fundamental na migração e homing das CTHs. ${ }^{39}$

Além desta, várias outras sinalizações têm mostrado importância nas interações entre células do nicho e as CTHs.

Jung et al.$^{40}$ identificaram anexina 2 como um fator adesivo na interação CTH-osteoblasto. Este fator expresso nos osteoblastos e em células endoteliais é importante para a estabilização da CTH no nicho.

Em paralelo a fatores derivados do nicho, alguns fatores produzidos pelas CTHs também se mostram importantes na interação CTH-nicho. Entre estes podem-se destacar moléculas de adesão como $\beta$-integrina e $\mathrm{N}$-caderina, que são importantes para a localização e o homing. Animais nocautes para a Rho-GTPase, cdc42, apresentam expressão diminuída destes genes e, coincidentemente, menor adesão das CTHs à fibronectina. ${ }^{41}$

Além disso, as CTHs expressam o receptor tirosina quinase Tie $2,{ }^{42}$ que interage com seu ligante angiopoetina-1 secretado pelos osteoblastos localizados na proximidade do nicho.

Todas estas interações podem ter o papel de manter as CTHs do nicho em um estado quiescente. No entanto, a mobilização, proliferação e a diferenciação destas células, para acontecer, precisam de outros sinais que ativem novos programas genéticos.

Análises de camundongos nocaute para membros da sinalização BMP mostram um número aumentado de osteoblastos e de CTHs, sugerindo que os osteoblastos são um componente crítico do nicho medular. ${ }^{43}$

Mais especificamente, os osteoblastos estromais expressam diversos fatores solúveis como G-CSF, IL-6 e o ligante de Notch, Jagged1, que podem influenciar a proliferação e diferenciação de CTH. Reciprocamente, as CTHs regulam a secreção osteoblástica.

\section{Velhos e novos fatores importantes para a expansão e manutenção das LT-CTHs}

Nos últimos anos, diferentes abordagens em modelos animais invertebrados e vertebrados durante o desenvolvimento nos diferentes sítios hematopoéticos permitiram a identificação de vários outros fatores extrínsecos que estimulam a expansão de CTHs. Experimentos nos quais vários componentes foram ativados ou suprimidos revelaram uma grande complexidade na rede de sinalização que define o destino das CTHs in vivo e in vitro. Estes novos conhecimentos prometem uma nova era tanto no estudo das origens pato- fisiológicas de algumas doenças como na expectativa de obtenção de novos protocolos mais efetivos de expansão de CTHs para uso terapêutico.

Apesar de muitos genes poderem influenciar a cinética das CTHs, alguns são sérios candidatos a controlar a amplificação das CTHs para uso terapêutico. Estes podem ser divididos em três classes: genes que codificam fatores de transcrição, como o gene HoxB4; genes que codificam moléculas de sinalização, como as citocinas hematopoéticas, as proteínas da família WNT e os receptores da família Notch; e genes que regulam o ciclo celular, como $p 18$ e $p 21$.

Os genes Hox codificam para uma família de fatores de transcrição altamente conservada. Um particular gene desta família, o $\operatorname{Hox} B 4$, tem sido exaustivamente estudado devido à sua capacidade de aumentar a autorrenovação de CTHs. Experimentos em camundongos letalmente irradiados mostraram que a recuperação hematológica era mais rápida quando as células da medula óssea infundidas haviam sido transformadas com um vetor expressando HoxB 4 do que quando esta transformação era efetuada com um vetor controle. Neste experimento, o número de CTHs encontradas na medula óssea do animal controle foi menor que $10 \%$ do encontrado nos animais experimentais. ${ }^{44}$

Apesar do mecanismo pelo qual HoxB 4 induz a expansão de CTHs não ser bem conhecido, a transdução de células em cultura com o mesmo vetor expressando o gene foi capaz de gerar uma expansão de até duas mil vezes. ${ }^{45}$

Outra estratégia para amplificar CTHs é baseada na sinalização WNT. Esta via de sinalização controla vários processos biológicos, incluindo a determinação, migração e adesão celular.

Lesões genéticas em membros desta via estão associadas à transformação em várias neoplasias, incluindo as leucemias. Dezenove genes Wht estão presentes no genoma de mamíferos e produzem proteínas secretadas que são ligantes dos receptores frizzled.

$\mathrm{Na}$ ausência de sinais WNT, a $\beta$-catenina intracitoplasmática é direcionada para a degradação pelo proteossomo. Quando os ligantes WNT sinalizam, a degradação de $\beta$ catenina é inibida e seu acúmulo no citoplasma induz sua translocação para o núcleo num complexo com o fator de transcrição TCF. ${ }^{46}$ Como resultado, vários genes são regulados.

A via de WNT está envolvida com a geração e expansão das CTHs. ${ }^{47}$ Em camundongos com ativação prolongada da sinalização WNT/ $\beta$-catenina, um aumento de LT-CTHs foi verificado mas com falhas na diferenciação e na capacidade de regeneração do sistema hematopoético. ${ }^{48}$ Zhao et a $l^{49}$ mostraram que CTHs deficientes em $\beta$-catenina têm defeitos na manutenção e crescimento a longo prazo.

Várias proteínas WNT e frizzled são expressas em CTHs e células estromais fetais e adultas. Este padrão de expressão indica um efeito tanto parácrino quanto autócrino dos ligantes, como WNT5A, WNT2B, WNT10B, que mostraram 
promover a proliferação de CTHs e de progenitores multilinhagem quando adicionados a culturas in vitro, assim como manter o fenótipo imaturo destas células. ${ }^{50}$

Esses dados indicam que a sinalização WNT tem um papel importante na biologia da CTH; no entanto, que programas genéticos são ativados por esta sinalização ainda são um campo em exploração.

Alguns resultados indicam que $\mathrm{WNT} / \beta$-catenina é capaz de ativar a sinalização Notch, pois os genes alvos desta via, Hes 1 e Dtxl, são superexpressos quando ligantes WNT são adicionados a cultivos in vitro de CTHs. ${ }^{51}$ Também os genes HoxB4 e Bmil são superexpressos nestas células, sugerindo que eles também sejam regulados por WNT.

Notch é uma proteína da superfamília das imunoglobulinas, importante na sinalização célula a célula. Seus ligantes Delta e Jagged, quando interagindo com Notch, ativam sinalizações importantes no desenvolvimento e na linfopoese.

Recentemente, a adição de Delta1, um ligante de Notch, à mistura tradicional de citocinas, foi capaz de incrementar em seis vezes a expansão de CTHs de SCUP cultivadas em meio livre de soro..$^{52}$ Estes e outros resultados sugerem que a sinalização Notch, além de seu papel já conhecido na linfopoese, esteja envolvido na geração, antidiferenciação e expansão de CTHs. É importante ressaltar que existe um efeito de dose dos ligantes de Notch na cultura de CTHs. Enquanto baixas doses de Delta1 induzem a expansão de CTHs de SCUP, altas doses dessa citocina induzem apoptose. ${ }^{53}$ Além disso, como camundongos condicionais para Notch1 e Jagged1 têm atividade de CTHs normais in vivo, é provável que ocorra redundância funcional das diferentes isoformas de Notch e seus ligantes. ${ }^{54}$

Como para a autorrenovação das CTHs divisões celulares são necessárias, genes controlando o ciclo celular são bons candidatos a estarem envolvidos na cinética das CTHs.

Quando células da medula óssea de camundongos deficientes em p21 são analisadas, um número elevado de CTHs no ciclo são encontradas enquanto o número de progenitores é normal, mas com índice de divisão diminuído..$^{55}$ Este resultado sugere que $\mathrm{p} 21$ exerça um efeito específico nas CTHs.

A partir deste resultado, vários outros controladores do ciclo foram avaliados. Apesar de variações na capacidade de autorrenovação das CTHs quando os diferentes CKIs são inibidos in vitro ou in vivo, os resultados mais claros são os que definem o papel de $\mathrm{p} 18$. O camundongo deficiente em $\mathrm{p} 18$ tem um número aumentado de CTHs na medula óssea e maior competitividade de suas células em experimentos de repopulação. ${ }^{56}$ Estes e outros resultados indicam que p18 tem um papel central na inibição da autorrenovação das CTHs.

Por outro lado, p16/ARF parecem ser responsáveis por inibir a proliferação das CTHs e induzir sua apoptose. Efeito este que parece ser revertido pela expressão de Bmil, que é um repressor de p16/ARF. ${ }^{57}$
Com base nestes resultados pode-se sugerir que a inibição de p18, p21 e p16/ARF poderia ser útil na expansão de CTHs em cultura.

\section{Conclusões}

O uso de abordagens genéticas, particularmente a análise de camundongos com perda ou ganho de função em genes específicos, identificou uma série de novos atores relacionados com a capacidade de autorrenovação, sobrevivência, diferenciação, migração, adesão e apoptose das CTHs. O uso destes conhecimentos em abordagens experimentais in vitro, seja pela adição de novos fatores nos meios de cultura seja pela utilização de células capazes de produzir os fatores propostos, pode suplantar as dificuldades de obtenção de expansões de CTHs in vitro nas quantidades necessárias para uso terapêutico.Várias abordagens experimentais neste sentido já estão sendo realizadas e nos próximos anos podemos esperar um grande desenvolvimento nesta área.

\begin{abstract}
Hematopoietic stem cells (HSCs) have the potential for reconstituting the hematopoietic system a characteristic that has enabled the development of cell based therapies for neoplastic and non-malignant diseases. In parallel with these clinical advances, elucidation of molecular mechanisms controlling self-renewal, differentiation or apoptosis have contributed to our understanding of the molecular events that control HSC kinetics. This review focuses on how these advances can be translated in new strategies for HSC expansion and their use in therapies. Rev. Bras. Hematol. Hemoter. 2009; 31 (Supl. 1):2-8.
\end{abstract}

Key words: Hematopoietic stem cells; expansion; cell therapy.

\section{Referências Bibliográficas}

1. Cabrita GJ, Ferreira BS, da Silva CL, Gonçalves R, Almeida-Porada G, Cabral JM. Hematopoietic stem cells: from the bone to the bioreactor. Trends Biotechnol. 2003;21(5):233-40.

2. Reya T, Morrison SJ, Clarke MF, Weissman IL. Stem cells, cancer, and cancer stem cells. Nature. 2001;414(6859):105-11.

3. Müller-Sieburg CE, Cho RH, Thoman M, Adkins B, Sieburg HB. Deterministic regulation of hematopoietic stem cell self-renewal and differentiation. Blood. 2002;100(4):1302-9.

4. Wognum AW, Eaves AC, Thomas TE. Identification and isolation of hematopoietic stem cells. Arch Med Res. 2003;34(6):461-75.

5. Wang JC, Doedens M, Dick JE. Primitive human hematopoietic cells are enriched in cord blood compared with adult bone marrow or mobilized peripheral blood as measured by the quantitative in vivo SCID-repopulating cell assay. Blood. 1997;89(11):3919-24.

6. Thomas ED, Lochte HL Jr, Cannon JH, Sahler OD, Ferrebee JW. Supralethal whole body irradiation and isologous marrow transplantation in man. J Clin Invest. 1959;38:1709-16.

7. Gluckman E. Hematopoietic stem-cell transplants using umbilicalcord blood. N Engl J Med. 2001;344(24):1860-1. 
8. Douek DC, Vescio RA, Betts MR, Brenchley JM, Hill BJ, Zhang L, et al. Assessment of thymic output in adults after haematopoietic stem-cell transplantation and prediction of T-cell reconstitution. Lancet. 2000;355(9218):1875-81.

9. Lang P, Schumm M, Taylor G, Klingebiel T, Neu S, Geiselhart A, et al. Clinical scale isolation of highly purified peripheral CD34+ progenitors for autologous and allogeneic transplantation in children. Bone Marrow Transplant. 1999;24(6):583-9.

10. Roux E, Dumont-Girard F, Starobinski M, Siegrist CA, Helg C, Chapuis B, et al. Recovery of immune reactivity after T-celldepleted bone marrow transplantation depends on thymic activity. Blood. 2000;96(6):2299-303.

11. Handgretinger R, Klingebiel T, Lang P, Schumm M, Neu S, Geiselhart A, et al. Megadose transplantation of purified peripheral blood CD34(+) progenitor cells from HLA-mismatched parental donors in children. Bone Marrow Transplant. 2001;27 (8):777-83

12. Gluckman E, Broxmeyer HA, Auerbach AD, Friedman HS, Douglas GW, Devergie A, et al. Hematopoietic reconstitution in a patient with Fanconi's anemia by means of umbilical-cord blood from an HLA-identical sibling. N Engl J Med. 1989;321(17):1174-8.

13. Wagner JE, Barker JN, DeFor TE, Baker KS, Blazar BR, Eide C, et al. Transplantation of unrelated donor umbilical cord blood in 102 patients with malignant and nonmalignant diseases: influence of CD34 cell dose and HLA disparity on treatment-related mortality and survival. Blood. 2002;100(5):1611-8.

14. Iscove NN, Nawa K. Hematopoietic stem cells expand during serial transplantation in vivo without apparent exhaustion. Curr Biol. 1997;7(10):805-8.

15. Lansdorp PM. Role of telomerase in hematopoietic stem cells Ann N Y Acad Sci. 2005;1044:220-7.

16. Ito K, Hirao A, Arai F, Takubo K, Matsuoka S, Miyamoto K, et al. Reactive oxygen species act through p38 MAPK to limit the lifespan of hematopoietic stem cells. Nat Med. 2006;12 (4):446-51.

17. Heike T, Nakahata T. Ex vivo expansion of hematopoietic stem cells by cytokines. Biochim Biophys Acta. 2002;1592(3):313-21.

18. Jacobsen SE, Ruscetti FW, Ortiz M, Gooya JM, Keller JR. The growth response of Lin-Thy-1+ hematopoietic progenitors to cytokines is determined by the balance between synergy of multiple stimulators and negative cooperation of multiple inhibitors. Exp Hematol. 1994;22(10):985-9.

19. Madlambayan GJ, Rogers I, Kirouac DC, Yamanaka N, Mazurier F, Doedens $\mathrm{M}$, et al. Dynamic changes in cellular and microenvironmental composition can be controlled to elicit in vitro human hematopoietic stem cell expansion. Exp Hematol. 2005; 33(10):1229-39.

20. Audet J, Zandstra PW, Eaves CJ, Piret JM. Advances in hematopoietic stem cell culture. Curr Opin Biotechnol. 1998;9 (2):146-51

21. Emerson SG. Ex vivo expansion of hematopoietic precursors, progenitors, and stem cells: the next generation of cellular therapeutics. Blood. 1996;87(8):3082-8.

22. Köhler T, Plettig R, Wetzstein W, Schaffer B, Ordemann R, Nagels $\mathrm{HO}$, et al. Defining optimum conditions for the ex vivo expansion of human umbilical cord blood cells. Influences of progenitor enrichment, interference with feeder layers, early-acting cytokines and agitation of culture vessels. Stem Cells. 1999;17(1):19-24.

23. Bodine DM, Karlsson S, Nienhuis AW. Combination of interleukins 3 and 6 preserves stem cell function in culture and enhances retrovirus-mediated gene transfer into hematopoietic stem cells. Proc Natl Acad Sci USA. 1989;86(22):8897-901.

24. Bodine DM, Orlic D, Birkett NC, Seidel NE, Zsebo KM. Stem cell factor increases colony-forming unit-spleen number in vitro in synergy with interleukin-6, and in vivo in S1/Sld mice as a single factor. Blood. 1992;79(4):913-9.

25. Ema H, Takano H, Sudo K, Nakauchi H. In vitro self-renewal division of hematopoietic stem cells. J Exp Med. 2000;192(9): 1281-8.

26. Murray LJ, Young JC, Osborne LJ, Luens KM, Scollay R, Hill BL. Thrombopoietin, flt3, and kit ligands together suppress apoptosis of human mobilized CD34+ cells and recruit primitive CD34+ Thy1+ cells into rapid division. Exp Hematol. 1999;27(6):1019-28.

27. Fox N, Priestley G, Papayannopoulou T, Kaushansky K. Thrombopoietin expands hematopoietic stem cells after transplantation. J Clin Invest. 2002;110(3):389-94.

28. Sorrentino BP. Clinical strategies for expansion of haematopoietic stem cells. Nat Rev Immunol. 2004;4(11):878-88.

29. Hassan HT, Zander A. Stem cell factor as a survival and growth factor in human normal and malignant hematopoiesis. Acta Haematol. 1996;95(3-4):257-62.

30. Solar GP, Kerr WG, Zeigler FC, Hess D, Donahue C, de Sauvage FJ, et al. Role of c-mpl in early hematopoiesis. Blood. 1998;92 (1):4-10.

31. Petit-Cocault L, Volle-Challier C, Fleury M, Péault B, Souyri M. Dual role of $\mathrm{Mpl}$ receptor during the establishment of definitive hematopoiesis. Development. 2007;134(16):3031-40.

32. Almeida-Porada G, Brown RL, MacKintosh FR, Zanjani ED. Evaluation of serum-free culture conditions able to support the ex vivo expansion and engraftment of human hematopoietic stem cells in the human-to-sheep xenograft model. J Hematother Stem Cell Res. 2000;9(5):683-93.

33. Dexter TM, Allen TD, Lajtha LG. Conditions controlling the proliferation of haemopoietic stem cells in vitro. J Cell Physiol. 1977;91(3):335-44.

34. Bentley SA. Close range cell:cell interaction required for stem cell maintenance in continuous bone marrow culture. Exp Hematol. 1981;9(3):308-12.

35. Weisel KC, Gao Y, Shieh JH, Moore MA. Stromal cell lines from the aorta-gonado-mesonephros region are potent supporters of murine and human hematopoiesis. Exp Hematol. 2006;34(11):1505-16.

36. Takagi M. Cell processing engineering for ex vivo expansion of hematopoietic cells. J Biosci Bioeng. 2005;99(3):189-96.

37. Sacchetti B, Funari A, Michienzi S, Di Cesare S, Piersanti S, Saggio I, et al. Self-renewing osteoprogenitors in bone marrow sinusoids can organize a hematopoietic microenvironment. Cell. 2007; 131(2):324-36.

38. Sugiyama T, Kohara H, Noda M, Nagasawa T. Maintenance of the hematopoietic stem cell pool by CXCL12-CXCR4 chemokine signaling in bone marrow stromal cell niches. Immunity. 2006;25 (6):977-88.

39. Adams GB, Scadden DT. The hematopoietic stem cell in its place. Nat Immunol. 2006;7(4):333-7.

40. Jung Y, Wang J, Song J, Shiozawa Y, Wang J, Havens A, et al. Annexin II expressed by osteoblasts and endothelial cells regulates stem cell adhesion, homing, and engraftment following transplantation. Blood. 2007;110(1):82-90.

41. Yang L, Wang L, Geiger H, Cancelas JA, Mo J, Zheng Y. Rho GTPase Cdc42 coordinates hematopoietic stem cell quiescence and niche interaction in the bone marrow. Proc Natl Acad Sci USA. 2007;104(12):5091-6.

42. Arai F, Hirao A, Ohmura M, Sato H, Matsuoka S, Takubo K, et al. Tie2/angiopoietin-1 signaling regulates hematopoietic stem cell quiescence in the bone marrow niche. Cell. 2004;118(2):149-61.

43. Ross J, Li L. Recent advances in understanding extrinsic control of hematopoietic stem cell fate. Curr Opin Hematol. 2006;13(4): 237-42. 
44. Sauvageau G, Thorsteinsdottir U, Eaves CJ, Lawrence HJ, Largman C, Lansdorp PM, et al. Overexpression of HOXB4 in hematopoietic cells causes the selective expansion of more primitive populations in vitro and in vivo. Genes Dev. 1995; 9(14):1753-65.

45. Amsellem S, Pflumio F, Bardinet D, Izac B, Charneau P, Romeo $\mathrm{PH}$, et al. Ex vivo expansion of human hematopoietic stem cells by direct delivery of the HOXB4 homeoprotein. Nat Med. 2003; 9(11):1423-7.

46. Staal FJ, Luis TC, Tiemessen MM. WNT signalling in the immune system: WNT is spreading its wings. Nat Rev Immunol. 2008; 8(8):581-93.

47. Staal FJ, Clevers HC. WNT signalling and haematopoiesis: a WNTWNT situation. Nat Rev Immunol. 2005;5(1):21-30.

48. Scheller M, Huelsken J, Rosenbauer F, Taketo MM, Birchmeier W, Tenen DG, et al. Hematopoietic stem cell and multilineage defects generated by constitutive beta-catenin activation. Nat Immunol. 2006;7(10):1037-47.

49. Zhao C, Blum J, Chen A, Kwon HY, Jung SH, Cook JM, et al. Loss of beta-catenin impairs the renewal of normal and CML stem cells in vivo. Cancer Cell. 2007;12(6):528-41.

50. Van Den Berg DJ, Sharma AK, Bruno E, Hoffman R. Role of members of the Wnt gene family in human hematopoiesis. Blood. 1998;92(9):3189-202.

51. Trowbridge JJ, Xenocostas A, Moon RT, Bhatia M. Glycogen synthase kinase-3 is an in vivo regulator of hematopoietic stem cell repopulation. Nat Med. 2006;12(1):89-98.

52. Suzuki T, Yokoyama Y, Kumano K, Takanashi M, Kozuma S, Takato $\mathrm{T}$, et al. Highly efficient ex vivo expansion of human hematopoietic stem cells using Delta1-Fc chimeric protein. Stem Cells. 2006;24(11):2456-65.

53. Chiba S. Notch signaling in stem cell systems. Stem Cells. 2006; 24(11):2437-47.

54. Mancini SJ, Mantei N, Dumortier A, Suter U, MacDonald HR, Radtke F. Jagged1-dependent Notch signaling is dispensable for hematopoietic stem cell self-renewal and differentiation. Blood. 2005;105(6):2340-2.

55. Cheng T, Rodrigues N, Shen H, Yang Y, Dombkowski D, Sykes M, et al. Hematopoietic stem cell quiescence maintained by p21cip1/ waf1. Science. 2000;287(5459):1804-8.

56. Yuan Y, Shen H, Franklin DS, Scadden DT, Cheng T. In vivo selfrenewing divisions of haematopoietic stem cells are increased in the absence of the early G1-phase inhibitor, p18INK4C. Nat Cell Biol. 2004;6(5):436-42.

57. Jacobs JJ, Kieboom K, Marino S, DePinho RA, van Lohuizen M. The oncogene and Polycomb-group gene bmi-1 regulates cell proliferation and senescence through the ink 4 a locus. Nature. 1999;397(6715):164-8.

Avaliação: O tema apresentado consta da pauta elaborada pelo editor, Professor Milton Artur Ruiz, e coeditores deste suplemento, Professores Sergio Paulo Bydlowski e Adriana Seber.

Conflito de interesse: não declarado

Recebido: 28/08/2008

Aceito: 03/10/2008 